\title{
Quinine-Loaded Polymeric Nanoparticles: Validation of a simple HPLC-PDA Method to Determine Drug Entrapment and Evaluation of its Photostability
}

\author{
Luana Roberta Michels ${ }^{2}$, Lisiane Bajerski ${ }^{1}$, Tamara Ramos Maciel ${ }^{1}$, Letícia Marques Colomé ${ }^{1,2}$, Sandra Elisa Haas ${ }^{1,2^{*}}$ \\ ${ }^{1}$ Curso de Farmácia, Universidade Federal do Pampa, UNIPAMPA, CEP 97500-970, Uruguaiana, RS, Brazil. ${ }^{2}$ Programa de Pós-graduação em Ciências \\ Farmacêuticas, Universidade Federal do Pampa-UNIPAMPA, CEP 97500-970, Uruguaiana, RS, Brazil.
}

\section{ARTICLE INFO \\ Article history: \\ Received on: 01/11/2015 \\ Revised on: 26/11/2015 \\ Accepted on: 22/12/2015 \\ Available online: 27/02/2016}

Key words:

Nanocapsules, quinine,

validation, HPLC-DAD.

\begin{abstract}
Liquid chromatographic method was developed and validated for quantitative determination of quinine in polymeric nanoparticles. The method was performed using a Waters RP-18 column using a mobile phase consisting of acetonitrile:water:triethylamine $(60: 40: 0.01 \mathrm{v} / \mathrm{v} / \mathrm{v}$, and $\mathrm{pH}$ aqueous phase adjusted to 3.0 with phosphoric acid). The flow rate was $1.0 \mathrm{~mL} \mathrm{~min}^{-1}$ and the detection was achieved with a UV-PDA set at $232 \mathrm{~nm}$. The response was linear over a range of 12.0 to $24.0 \mu \mathrm{g} \cdot \mathrm{mL}^{-1}(\mathrm{r}=0.9995)$. The relative standard deviation values for intra-day and inter-day precision studies were less than $2 \%$ and the accuracy was $98.8 \%$ to $\mathrm{Nc1}$ and $97.3 \%$ to Nc2. The samples free of quinine and quinine-loaded polymeric nanoparticles were subjected to photodegradation conditions. A considerable reduction of degradation of quinine occurred in polymeric nanoparticles. Through these results, it was clear that the nanoencapsulation of quinine protects the drug from degradation by exposure to UV-A light. The analytical method was validated according to International Conference on Harmonization Guidelines and Center for Drug Evaluation and Research.
\end{abstract}

\section{INTRODUCTION}

Quinine (figure 1) is an alkaloid extracted from the bark of the cinchona and is the antimalarial drug that has been in use for over 400 years (Achan et al., 2012, De Oliveira, 2009). Generally it is used in monotherapy (Meshnick and Dobson, 2001), however, the adverse effects in high doses and the increasing parasite resistance to cinchona alkaloids have made necessary a combination with a second drug (WHO, 2012). This drug is used as a second line treatment of uncomplicated malaria and as preferential line treatment of malaria in (Taylor and White, 2004) the first trimester of pregnancy (WHO, 2010). It is rapidly absorbed orally and has a good tissue distribution, but is hardly accumulated, since it is rapidly metabolized and excreted (Salako and Sowunmi, 1992). The great advantage of quinine as an antimalarial is its adequate solubility for intravenous formulations and is of great importance in the treatment of

\footnotetext{
* Corresponding Author

Sandra Elisa Haas, Programa de Pós-graduação em Ciências

Farmacêuticas, Universidade Federal do Pampa-UNIPAMPA,

CEP 97500-970, Uruguaiana, RS, Brazil.

Email:sandrahaas@unipampa.edu.br
}

patients who do not tolerate oral medication (Wiesner et al., 2003). However, the required high doses administration by the intravenous route can cause severe cardiac arrhythmia and even fatal hypotension (Vale et al., 2005). Besides that, quinine is photo unstable (Christensen et al., 2000). From this, an improvement of the quinine therapeutic index could play an important role in the treatment of drug resistant malaria. The drug carrier system has been extensively studied as vectors that allow control of drug delivery to specific sites in the treatment of many diseases (Duncan and Gaspar, 2011). Among these, we highlight the carrier nanoparticulate systems which are defined as colloidal particles, or pharmacologically active with the ability to carry therapeutic agents, which is in the nanometer range of 10 to $1000 \mathrm{~nm}(1 \mu \mathrm{m})$ (Nagavarma et al., 2012, Caban et al., 2014). Quinine-loaded nanocapsules have been developed and shown to increase drug efficacy in rats infected with Plasmodium berghei (Haas et al., 2009). The essential characterization of drugs-loaded nanoparticles is particle size, zeta potential, polydispersibility, $\mathrm{pH}$, entrapment efficiency and drug loading (Hall et al., 2007). For the last two, the quantification techniques play an important role. Quantification of quinine is usually by liquid chromatography system with fluorescence detection (Haas et al., 2009, Mirghani et al., 1998). 
The MS detection is also used because of the high sensitivity and specificity of this technique for identification and quantification of drugs at low concentrations in raw materials, pharmaceutical formulations, and biological matrices (Brum et al., 2011). However, UV detection is often preferred, because it is cheaper and more easily available. No analytical techniques are described for dosing quinine in pharmaceutical formulations using high performance liquid chromatography (HPLC) and UV detection, which is sensitive to compounds that absorb light and are easy to operate as well as it possess a good stability and is more commonly used in HPLC analysis (Argenton, 2010).

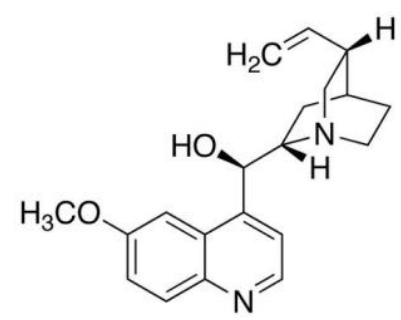

Fig 1: Chemical Structure of Quinine.

Thus, the goal of this study was to develop and validate a method for the determination of this quinine in nanoparticulate systems dosage forms using diode array UV detector as a new methodology, according to the current International Conference on Harmonization (ICH) guidelines (ICH, 1996, ICH, 2003, ICH, 2005), thereby contributing to the development of new alternatives techniques for the quality control of different pharmaceutical formulations based on cinchona alkaloids.

\section{MATERIAL AND METHODS}

\section{Chemical and Reagents}

The Quinine (QN) (90\% purity) was obtained from Sigma Aldrich Ltd (São Paulo, Brazil). Acetonitrile and methanol solvents were obtained from Tedia (Fairfield,USA). Purified water was prepared using a Milli-Q Plus (Millipore, Bedford, USA). All other reagents and chemicals used were of pharmaceutical or special analytical grade.

\section{Instrumentations}

The analysis were performed on a Shimadzu LC system (Kyoto, Japan), which consisted of a LC-20AT pump, a SPDM20A photodiode array (PDA) detector, a CBM-20A system controller, a DGU-20A3 degasser and a SIL-20A autosampler. Data were acquired and processed using LC Solution software (Release 1.22 SP1). Chromatographic separation was achieved on a $5 \mu \mathrm{m}$ Waters RP-18 column $(4.6 \mathrm{~mm} \times 300 \mathrm{~mm})$, with a guard column (4 $x 3 \mathrm{~mm}$ i.d.) packed with the same material. Photodegradation was carried out in a photostability UV chamber $(1.0 \times 0.17 \times 0.17 \mathrm{~m})$ with mirrors and equipped with an UV-A lamp (Orion, $352 \mathrm{~nm}, 30 \mathrm{~W}, 130 \mathrm{~V}$ ) and UV cuvettes (BRAND®), used as a container for samples.

\section{Chromatographic Conditions}

The chromatographic analysis was performed at the standard temperature $\left(23 \pm 1^{\circ} \mathrm{C}\right)$, using a mobile phase composed of acetonitrile:water:triethylamine (60:40:0.01 v/v/v). The aqueous phase was adjusted to $\mathrm{pH} 3.0$ with phosphoric acid). After preparation, the mobile phase was filtered through a $0.45 \mu \mathrm{m}$ membrane filter (Millipore, Bedford, USA) and degassed using an ultrasonic bath for $20 \mathrm{~min}$. The flow rate was $1.0 \mathrm{~mL}$ $\min ^{-1}$ and quinine was detected at $232 \mathrm{~nm}$ after injection of $20 \mu \mathrm{L}$.

\section{Preparation of Quinine-Loaded Nanocapsules}

Two different nanocapsules were prepared by interfacial deposition of PCL (Fessi et al., 1988; Haas et al., 2009), denominated formulation $1\left(\mathrm{Nc}_{1} \mathrm{QN}\right)$ and formulation $2\left(\mathrm{Nc}_{2} \mathrm{QN}\right)$. The organic phase $\mathrm{Nc}_{1} \mathrm{QN}$ was composed of poly ( $\varepsilon$-caprolactone) (PCL) $(0.1 \mathrm{~g})$, Lipoid $\mathrm{S} 45^{\circledR}$ surfactant $(0.078 \mathrm{~g})$, quinine (2 $\left.\mathrm{mg} \cdot \mathrm{mL}^{-1}\right)$, caprylic/capric triglyceride $(330 \mu \mathrm{L})$, prepared in acetone $(27 \mathrm{~mL})$ in temperature of $45 \pm 1{ }^{\circ} \mathrm{C}$, which was added to the aqueous phase composed of distilled water $(53 \mathrm{~mL})$, polysorbate 80 (Tween $\left.80^{\circledR}\right)(0.078 \mathrm{~g})$ and polietilenoglicol (PEG $4000)(0.07 \mathrm{~g})$. In the organic phase $\mathrm{Nc}_{2} \mathrm{QN}$, the PCL polymer was replaced with the positively charged polymer Eudragit RS100 ${ }^{\circledR}$ $(0.1 \mathrm{~g})$, the surfactant Lipoid $\mathrm{S} 45^{\circledR}$ was replaced by Span $60^{\circledR}$ $(0.078 \mathrm{~g})$. The aqueous phase was composed of distilled water (53 $\mathrm{mL})$ and Tween $80 \AA(0.078 \mathrm{~g})$. Nanocapsules without $\mathrm{QN}$ were also prepared and designed blank nanocapsules $\left(\mathrm{NC}_{1} \mathrm{BR}\right.$ or $\left.\mathrm{NC}_{2} \mathrm{BR}\right)$.

\section{Preparation of Standard Solution and Samples}

Stock solution of QN (1000 $\left.\mu \mathrm{g} \cdot \mathrm{mL}^{-1}\right)$ was prepared by dissolving accurately weighed $10 \mathrm{mg}$ in acetonitrile using $10 \mathrm{~mL}$ volumetric flask. Standard solution was prepared by dilution of the diluted stock solution with mobile phase to obtain solutions in a final concentration of $20 \mu \mathrm{g} \mathrm{mL}^{-1}$. To prepare the sample solutions, $0.1 \mathrm{~mL}$ of nanoparticulate systems (2 mg. $\mathrm{mL}^{-1}$ of $\left.\mathrm{QN}\right)$ was transferred into a $10 \mathrm{~mL}$ volumetric flask, with $10 \mathrm{~mL}$ of acetonitrile, obtaining the final concentration of $20 \mu \mathrm{g} \cdot \mathrm{mL}^{-1}$. This flask was kept in an ultrasonic bath for $30 \mathrm{~min}$. The solutions were filtered through a $0.45 \mu \mathrm{m}$ membrane filter before injection.

\section{VALIDATION OF THE METHOD}

The developed chromatographic method was validated using quinine-loaded nanocapsules $\mathrm{NC}_{1} \mathrm{QN}$ and $\mathrm{NC}_{2} \mathrm{QN}$ with the label claim of $2 \mathrm{mg} . \mathrm{mL}^{-1}$, by determination of specificity, linearity, precision, accuracy, robustness and system suitability, following ICH guidelines.

\section{Linearity and sensitivity}

Linearity was evaluated by constructing three calibration curves, each one with 7 concentration levels of QN $(12,13.5,15$, $16.5,18,21,24 \mu \mathrm{g} \cdot \mathrm{mL}^{-1}$ ) on three different days. The results were tested by ANOVA and linear regression analysis was used to obtain the linear equation and correlation coefficient. The limits of 
detection (LOD) and quantitation (LOQ) were calculated using the direct calibration line. The LOQ was calculated by multiplying the factor 10 for the intercept and dividing the value obtained by the slope of the average. The same procedure was used for the calculation of LOD, however the factor used was 3.3, according to the guidelines (ICH, 1996, ICH, 2003, ICH, 2005).

\section{Precision}

The intra-day precision was analyzed through the preparation of 6 samples of nanocapsules $\left(\mathrm{Nc}_{1} \mathrm{QN}\right.$ e $\left.\mathrm{Nc}_{2} \mathrm{QN}\right)$ containing $20 \mu \mathrm{g} \cdot \mathrm{mL}^{-1}$ of $\mathrm{QN}$, on the same day $(\mathrm{n}=6)$. Inter-day precision was tested by repeating the same procedure on 3 different days $(n=6 /$ day $)$ and comparing the results for the different days. The precision data were expressed as relative standard deviation percentage (RSD\%).

\section{Accuracy}

The accuracy of the method was evaluated by adding a known amount of QN at three concentrations $\left(16,20,24 \mu \mathrm{g} \cdot \mathrm{mL}^{-1}\right)$ to blank nanocapsules samples corresponding to 80,100 and $120 \%$ of the nominal analytical concentration $\left(20 \mu \mathrm{g} \cdot \mathrm{mL}^{-1}\right)$. Each solution was prepared in triplicate and the concentrations and recoveries were calculated against the added concentration.

\section{Robustness}

Robustness of the proposed method was examined by evaluating the influence of small alterations of the most important procedure variables such as the ratio of mobile phase ACN: MeOH: water pH 3.0 (40:40:20 and 50:30:20), flow change (0.8 and $1.2 \mathrm{ml} / \mathrm{min}$ ) and $\mathrm{pH}$ (2.8 and 3.2). Analyses of nanocapsules containing $20 \mu \mathrm{g} \cdot \mathrm{mL}^{-1}$ QN were carried as the same form described above (item 2.5), in triplicate. Only one parameter in the experiments was changed at a time and the effects were studied based on RSD (\%) values obtained among the parameters analyzed. In order to evaluate the robustness the values obtained after different tests were compared in relation to Rt (retention time), $\mathrm{T}$ (tailing factor $\leq 2.0$ ), $\mathrm{k}$ (retention factor $\geq 2.0$ ) and $\mathrm{N}$ (theoretical plate number $\geq 2000$ ) according to the limits established by FDA (FDA, 1994).

\section{Specificity}

The specificity was performed by observing interferences from quinine-loaded nanocapsules excipients. The chromatograms of excipient placebo solution (without drug) and antimalarial solutions were compared to verify the probable interference of the excipients on the drug quantitation.

\section{Nanocapsules applicability}

Photodegradation was induced by exposing the samples to UV-A radiation $(352 \mathrm{~nm}$ ) for $8 \mathrm{~h}$. The samples of free $\mathrm{QN}$, $\mathrm{Nc}_{1} \mathrm{QN}$ and $\mathrm{Nc}_{2} \mathrm{QN}$ were added in cuvettes $(2 \mathrm{~mL})$ inside the chamber $(n=3)$. In specific times, an aliquot of each sample was withdraw for HPLC-PDA analysis. Samples were analyzed in comparison to the control sample (free $\mathrm{QN}$ ) which was also subjected to degradation conditions. After each time degradation, all samples were submitted to dilution in acetonitrile to yield a final concentration of $20 \mu \mathrm{g} \cdot \mathrm{mL}^{-1}$ and filtration in a $0.45 \mu \mathrm{m}$ membrane filter, before injection.

\section{RESULTS AND DISCUSSION}

The development and validation of the analytical method quinine-loaded nanocapsules allows a simple and rapid quantitative estimate. This novel method quantifies $\mathrm{QN}$ in different nanoparticle systems and uses photodiode array UV detection with optimal chromatographic conditions.

The nanocapsules have been characterized according to the diameter, $\mathrm{pH}$ and zeta potential. Both formulations have a diameter in the range between 150 and $200 \mathrm{~nm}$ and polydispersity -below 2 confirming the homogeneity of particle size distribution.

The $\mathrm{pH}$ of the formulations showed between 7 and 8 for both formulations because of the high basicity of quinine. The zeta potential indicates that the electrical potential of the particle surface was around -25 and $+15 \mathrm{mV}$ for $\mathrm{NC}_{1} \mathrm{QN}$ and $\mathrm{NC}_{2} \mathrm{QN}$, respectively.

This difference is because of the cationic polymer Eudragit $\mathrm{RS} 100^{\circledast}$, giving positive charge to $\mathrm{NC} 2 \mathrm{QN}$ and the polymer (PCL) and the surfactant (Lipoid $\left.\mathrm{S} 45^{\circledR}\right)$, responsible for the negative charge of $\mathrm{NC}_{1} \mathrm{QN}$ (Schaffazick et al., 2002, Mosqueira et al., 2001). These results are in agreement with Haas and co-workers (Haas et al., 2009).

The best chromatographic condition was achieved using a mobile phase consisting of acetonitrile and water $0.01 \%$ triethylamine (pH adjusted to 3.0 with phosphoric acid) (60:40, $\mathrm{v} / \mathrm{v})$, with a flow rate of $1.0 \mathrm{~mL} \mathrm{~min}{ }^{-1}$ and total run time of 08 minutes. QN produced a sharp and symmetric peak when chromatographed with these conditions.

A typical chromatogram of $\mathrm{QN}$ standard, $\mathrm{NC}_{1} \mathrm{QN}$ and $\mathrm{NC}_{2} \mathrm{QN}$ obtained by the proposed method is shown in Figure 2A, $2 \mathrm{~B}$ and $2 \mathrm{C}$, respectively. PDA detector enables the analysis of a drug at different wavelengths in a single analysis, as well as to verify peak purity during analysis, so we chose to use the wavelengths of maximum absorption for QN $(232 \mathrm{~nm})$ in order to obtain the maximum area for each peak. The retention time for quinine was 06 minutes.

QN linearity was evaluated in the concentration range of 12-24 $\mu \mathrm{g} \cdot \mathrm{mL}^{-1}$. The calibration curves constructed for $\mathrm{QN}$ were found to be linear and the equation obtained was $\mathrm{y}=$ $103.540,2232 x+68.439,8428$, where $y$ is the peak area ratio of $\mathrm{QN}$ and $\mathrm{x}$ is the concentration of $\mathrm{QN}$ in $\mu \mathrm{g} \cdot \mathrm{mL}^{-1}$. The correlation coefficient was 0.9995 .

The validity of the assay was verified by means of analysis of variance (ANOVA), which demonstrated that the regression equation was linear $\left(\mathrm{F}_{\text {calculated }}=1.05 .10^{2}>\mathrm{F}_{\text {critical }}=4.96\right.$; $\alpha=0.05)$ with no deviation from linearity $\left(\mathrm{F}_{\text {calculated }}=1.10 .10^{-2}<\right.$ $\mathrm{F}_{\text {critical }}=3.33 ; \alpha=0.05$ ). The LOD and LOQ were estimated to be 2.29 and $6.94 \mu \mathrm{g} \cdot \mathrm{mL}^{-1}$, respectively, indicating suitable sensitivity of the method. 

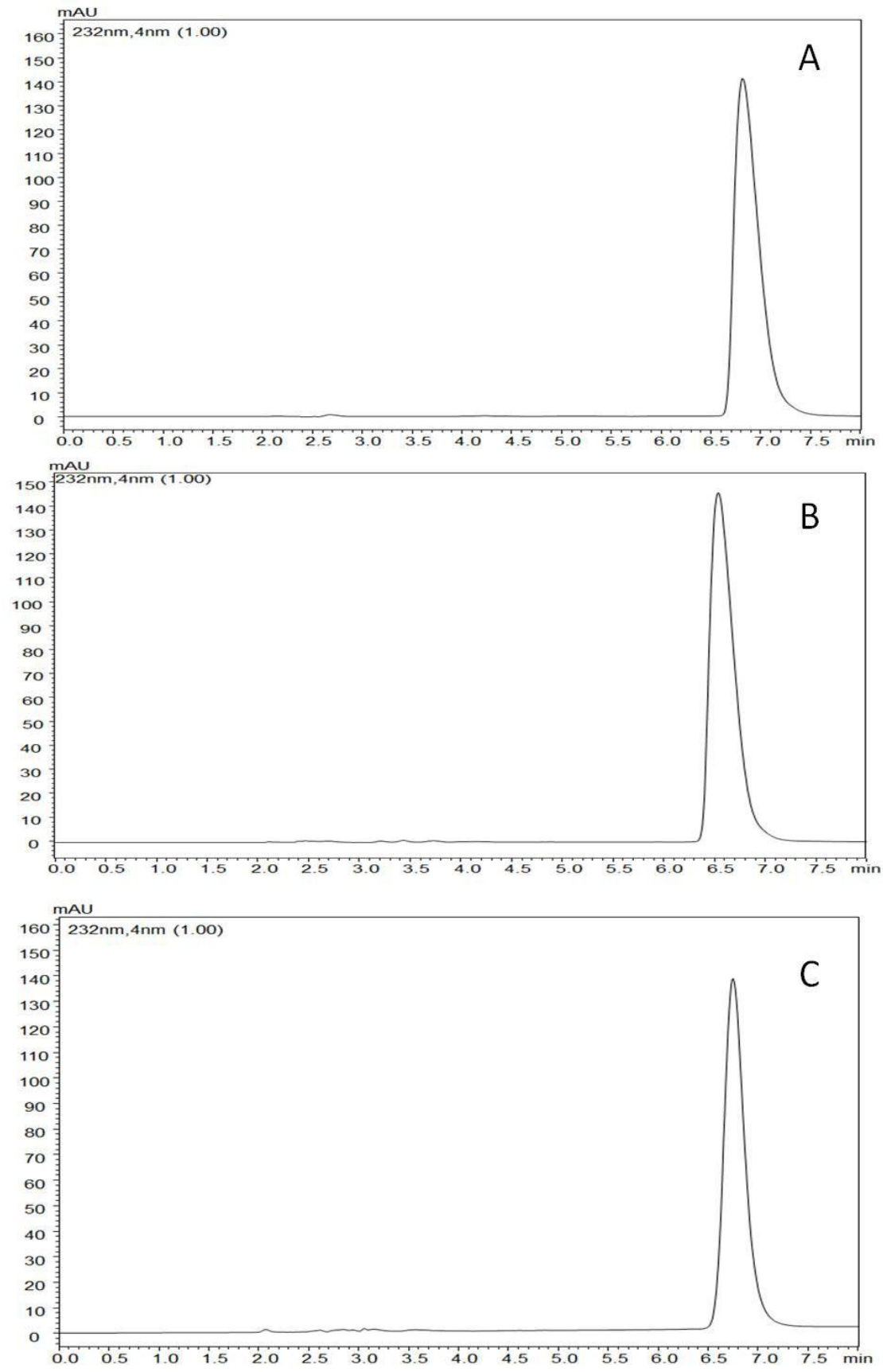

Fig. 2: Chromatogram of Quinine standard (A), $\mathrm{Nc}_{1} \mathrm{QN}(\mathrm{B})$ and $\mathrm{Nc}_{2} \mathrm{QN}(\mathrm{C})$ by the proposed method.

The repeatability of the method was determinate by the RSD for six determinations of QN performed on the same day and under the same experimental conditions (intra-day). The inter-day precision was assessed by analyzing six samples on three different days. These results are given in Table I. The low RSD (\%) was obtained for the intra-day $(<1.0 \%)$ and inter-day precision $\left(0.875 \%\right.$ for $\mathrm{Nc}_{1} \mathrm{QN}$ and $0.629 \%$ for $\left.\mathrm{Nc}_{2} \mathrm{QN}\right)$. The $\mathrm{Nc}_{1} \mathrm{QN}$ showed a slightly label claim concentration higher than $\mathrm{Nc}_{2} \mathrm{QN}$, but different particulate systems had a lower RSD\% in inter-day precision and in intra-day accuracy, confirming good precision of the quinine-loaded nanocapsules method. The accuracy was calculated as the percentage of recovery by the assay of adding a known amount of quinine at three concentrations to blank nanocapsules. The accuracy of the method ranged from 98 to $99.6 \%$ to $\mathrm{Nc}_{1}$ and from 97 to $97.8 \%$ to $\mathrm{Nc}_{2}$, with $\mathrm{RSD}$ lower than $2.0 \%$. The recovery of almost all the drug in the sample in three different (high, medium and low) concentrations with a low RSD \% indicates that the assay is accurate (Table II).

Robustness of the proposed analytical method was evaluated by changes in the chromatographic conditions as flow rate, mobile phase composition and $\mathrm{pH}$. The samples of $\mathrm{Nc}_{1} \mathrm{QN}$ and $\mathrm{Nc}_{2} \mathrm{QN}$ were performed in triplicate and injected for each of the changes and system suitability parameters evaluated. 
Table I: Repeatability/intermediate precision method for $\mathrm{Nc}_{1} \mathrm{QN}$ and $\mathrm{Nc}_{2} \mathrm{QN}$.

\begin{tabular}{|c|c|c|c|c|c|c|c|c|}
\hline \multicolumn{6}{|c|}{ \% Label claim $\left(\mathrm{Nc}_{1} \mathrm{QN}\right)\left(20 \mu \mathrm{g} . \mathrm{mL}^{-1}\right)$} & & \multirow{2}{*}{$\begin{array}{r}\text { Mean (\%) } \\
103.3\end{array}$} & \multirow{2}{*}{$\begin{array}{r}\mathbf{R S D}^{\mathbf{a}}(\boldsymbol{\%}) \\
0.438\end{array}$} \\
\hline Day I & 103.8 & 103.8 & 103.8 & 103.8 & 103.8 & 103.8 & & \\
\hline Day II & 103.3 & 103.3 & 103.3 & 103.3 & 103.3 & 103.3 & 103.4 & 0.126 \\
\hline Day III & 101.3 & 101.3 & 101.3 & 101.3 & 101.3 & 101.3 & 101.6 & 0.316 \\
\hline \multicolumn{7}{|c|}{ Mean inter-assay $(\%)(n=18)$} & \multicolumn{2}{|c|}{102.8} \\
\hline \multicolumn{7}{|c|}{ \% Label claim $\left(\mathrm{Nc}_{2} \mathrm{QN}\right)\left(20 \mu \mathrm{g} \cdot \mathrm{mL}^{-1}\right)$} & Mean (\%) & $\mathbf{R S D}^{\mathbf{a}}(\%)$ \\
\hline Day I & 97.4 & 97.4 & 97.4 & 97.4 & 97.4 & 97.4 & 97.7 & 0.332 \\
\hline Day II & 98.3 & 98.3 & 98.3 & 98.3 & 98.3 & 98.3 & 98.9 & 0.457 \\
\hline Day III & 98.7 & 98.7 & 98.7 & 98.7 & 98.7 & 98.7 & 98.6 & 0.108 \\
\hline \multicolumn{7}{|c|}{$\begin{array}{c}\text { Mean inter-assay }(\%)(\mathbf{n}=18) \\
\text { RSD }(\%)\end{array}$} & \multicolumn{2}{|c|}{$\begin{array}{c}98.4 \\
0.629\end{array}$} \\
\hline
\end{tabular}

RSD: Relative Standard Deviation

Table II: Results for the recovery test for QN.

\begin{tabular}{|c|c|c|c|}
\hline Amount concentration added $\left(\mu \mathrm{g} . \mathrm{mL}^{-1}\right)$ & Concentration $(\%)$ & Recovery $(\%)\left(\mathrm{Nc}_{1}\right)$ & Recovery $(\%)\left(\mathrm{Nc}_{2}\right)$ \\
\hline 16.0 & 80 & 99.6 & 97.8 \\
\hline 20.0 & 100 & 98.8 & 97.1 \\
\hline 24.0 & 120 & 98.0 & 97.0 \\
\hline \multicolumn{2}{|c|}{ Mean recovery $(\%)$} & 98.8 & 97.3 \\
\hline \multicolumn{2}{|c|}{$\operatorname{RSD}^{\mathbf{a}}(\%)$} & 0.805 & 0.455 \\
\hline
\end{tabular}

${ }^{a}$ RSD: Relative Standard Deviation

Table III: Evaluation of robustness for the nanocapsules-quinine loaded HPLC assay $(\mathrm{n}=3)$.

\begin{tabular}{|c|c|c|c|c|c|}
\hline \multirow[t]{2}{*}{ Conditions } & \multicolumn{5}{|c|}{$\mathrm{Nc}_{1} \mathbf{Q N}$} \\
\hline & $\mathbf{R}_{t}(\min .)^{\mathrm{c}}$ & $T(\leq 2.0)^{d}$ & $K(\geq 2.0)^{\mathrm{e}}$ & $N(\geq 2000)^{\mathrm{f}}$ & Mean (\%) \\
\hline Proposed method $^{\mathrm{a}}$ & 6.00 & 1.249 & 3.444 & 4008 & 102.0 \\
\hline $0.8 \mathrm{~mL} \mathrm{~min}^{-1}$ & 6.90 & 1.347 & 4.904 & 4588 & 103.7 \\
\hline $1.2 \mathrm{~mL} \mathrm{~min}^{-1}$ & 5.71 & 1.339 & 3.713 & 3970 & 102.6 \\
\hline Acn:MeOH:H $\mathrm{H}_{2} \mathrm{O}(50: 30: 20)$ & 5.56 & 1.233 & 3.568 & 4428 & 100.8 \\
\hline Acn:MeOH:H $\mathrm{H}_{2} \mathrm{O}(40: 40: 20)$ & 5.54 & 1.251 & 3.347 & 4042 & 102.7 \\
\hline pH (2.8) & 5.48 & 1.229 & 3.483 & 4264 & 102.0 \\
\hline pH (3.2) & 5.49 & 1.225 & 3.494 & 4278 & 100.3 \\
\hline \multirow[t]{3}{*}{ RSD \% } & & & & & 1.07 \\
\hline & \multicolumn{5}{|c|}{$\mathrm{Nc}_{2} \mathrm{QN}$} \\
\hline & $\mathbf{R}_{t}$ (min.) & $T(\leq 2.0)$ & $K(\geq 2.0)$ & $N(\geq 2000)$ & Mean (\%) \\
\hline Proposed method $^{\mathrm{a}}$ & 6.20 & 1.250 & 3.454 & 4095 & 98.2 \\
\hline $0.8 \mathrm{~mL} \mathrm{~min}^{-1}$ & 6.91 & 1.325 & 4.918 & 4616 & 101.7 \\
\hline $1.2 \mathrm{~mL} \mathrm{~min}^{-1}$ & 5.73 & 1.322 & 3.732 & 4049 & 99.6 \\
\hline Acn:MeOH:H ${ }_{2} \mathrm{O}(50: 30: 20)$ & 5.56 & 1.235 & 3.567 & 4370 & 97.6 \\
\hline Acn:MeOH:H $\mathrm{H}_{2} \mathrm{O}(40: 40: 20)$ & 5.55 & 1.254 & 3.351 & 4101 & 96.8 \\
\hline pH (2.8) & 5.48 & 1.223 & 3.485 & 4265 & 96.5 \\
\hline pH (3.2) & 5.49 & 1.239 & 3.493 & 4313 & 97.1 \\
\hline RSD \% & & & & & 1.76 \\
\hline
\end{tabular}

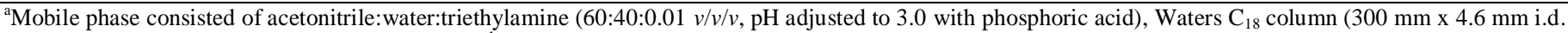

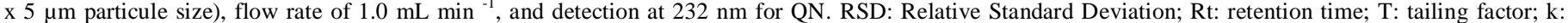
retention factor; $\mathrm{N}$ : theoretical plate number.

The values of the selected variables evaluated in the robustness assessment are shown in Table III. All conditions evaluated resulted in small changes in the retention time, tailing factor and theoretical plate number in comparison with the proposed analytical conditions. The results were satisfactory in accordance with the literature (ICH, 1996; ICH, 2003; ICH, 2005). No significant differences related to the quantification of quinine (RSD $<2.0 \%$ ) and none of these alterations caused a significant effect on the determination of this drug in nanocapsules, indicating the robustness of the method. The specificity of the method for QN was established through determination of the purity peak of the analyte in the working standard solution using a PDA detector.

No interference from formulation excipients was found in the same retention time of the drug, showing that the peaks were free from any co-eluting peak, demonstrating that the proposed method is specific for the analysis of QN. In photodegradation studies after 8 hours of exposure to UV-A light, quinine standard had a degradation of $27.11 \pm 0.218 \%$.
However, the nanocapsules samples had a degradation of $11.92 \pm 0.508 \%$ and $13.34 \pm 0.628 \%$ for $\mathrm{Nc}_{1} \mathrm{QN}$ and $\mathrm{Nc}_{2} \mathrm{QN}$, respectively. Even after 8 hours of exposure to UV-light there was no formation of degradation products for both the standard (Figure 3D) and the QN nanocapsules (Figure 3E and 3F), but only a decrease in the content of QN.

Through these results, it is clear that the nanoencapsulation of QN protects the drug from degradation by exposure to UV-A light. This indicates that the tested nanocapsules are alternative systems that protect sensitive drugs to light degradation. In the photodegradation was observed protection of quinine by the nanoparticles after 8 hours of exposure to UV-A radiation, which did not occur with the quinine standard, which had twice the degradation compared to nanoparticulate systems. Through these results, it is clear that the nanoencapsulation of QN protects the drug from degradation by exposure to UV-A light. This indicates that the tested nanocapsules are alternative systems that protect sensitive drugs to light degradation. 

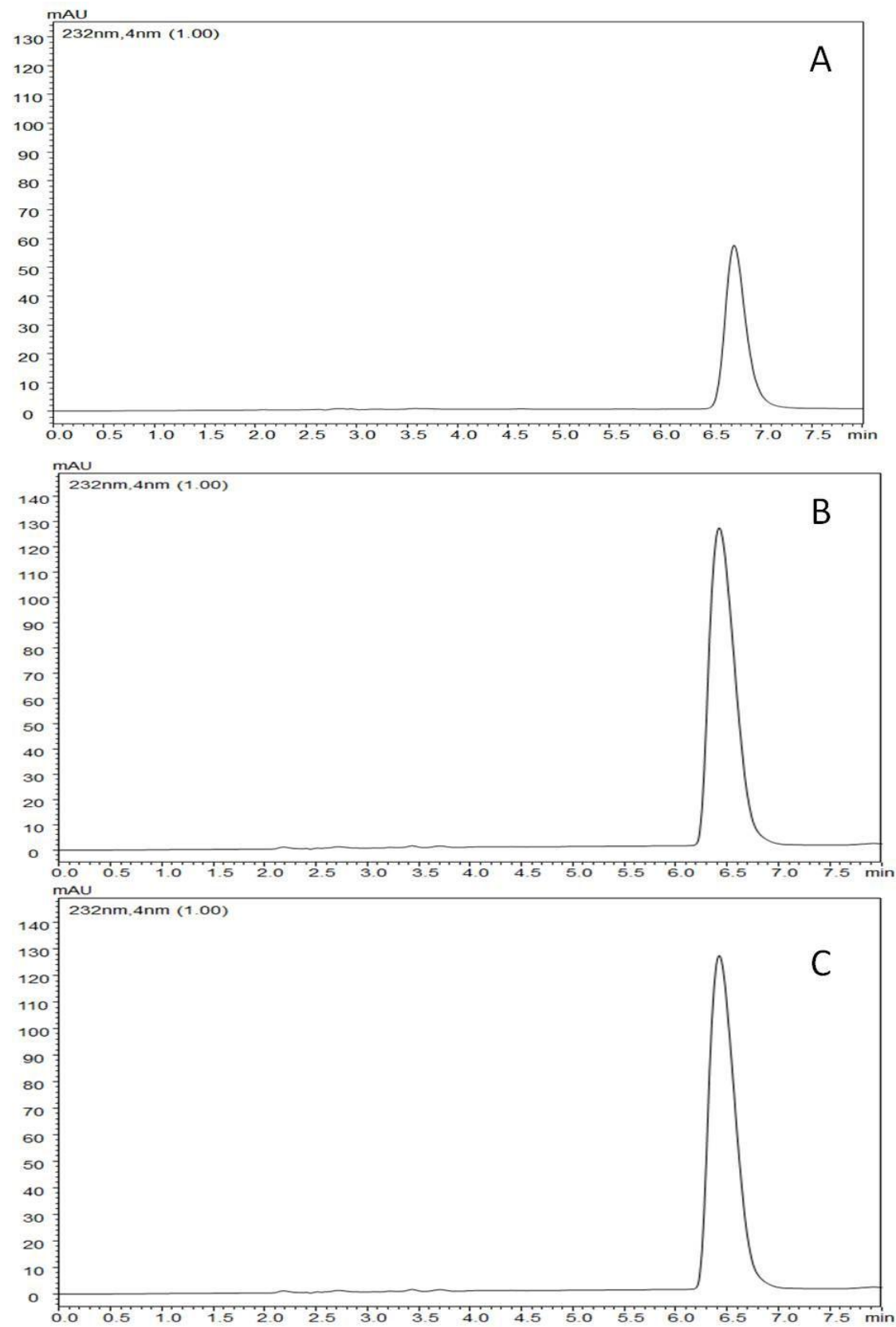

Fig. 3: Chromatogram of Quinine standard (D), $\mathrm{Nc}_{1} \mathrm{QN}(\mathrm{E})$ and $\mathrm{Nc}_{2} \mathrm{QN}(\mathrm{F})$ after 8 hours of exposure to UV-light.

\section{CONCLUSION}

The proposed HPLC method was developed and validated. It allows a simple and fast quantitative estimation of QN in innovative nanoparticulate systems using PDA detection. This system has a high absorbance and allows a greater selectivity due to the choice of wavelength and hence has a higher sensitivity and a lower cost, which makes it more usual.

This method can be employed conveniently with reliably and success for the estimation of QN in routine quality control and stability studies. Furthermore, according to the photodegradation testing, it was proved that the proposed nanocapsules-quinine loaded offer protection to QN degradation to light.

\section{ACKNOWLEDGMENTS}

This study was supported by the Brazilian agencies: Conselho Nacional de Desenvolvimento Científico e Tecnológico (CNPq), Coordenação de Aperfeiçoamento de Pessoal de Nível Superior (Capes) and Fundação de Amparo à Pesquisa do Estado do Rio Grande do Sul (FAPERGS).

\section{REFERENCES}

Achan J, Talisuna AO, Erhart A, Yeka A, Tibenderana JK, Baliraine FN, Rosenthal PJ, D'Alessandro U. Quinine, an old anti-malarial drug in a modern world: role in the treatment of malaria. Malaria Journal, 2011, 10:144. 
Argenton A. 2010. Conceitos fundamentais de Cromatografia líquida de Alto Desempenho (HPLC). Conselho Regional de Química - IV Região (SP) [in Portuguese].

Brum LLM, Uchoa FT, Kaiser M, Guterres SS, Dalla Costa T. Determination of Quinine and Doxycycline in Rat Plasma by LC-MSMS: Application to a Pharmacokinetic Study. Chromatographia, 2011, 73:1081-1088.

Caban SAE, Sahin A, Capan Y. Nanosystems for drug delivery. Drug Delivery, 2014, 2(1):2:7

Christensen K L, Christensen J O, Frokjaer S, et al. Influence of temperature and storage time after light exposure on the quinine monohydrochloride chemical actinometric system. European Journal of Pharmasceutical Sciences, 2000, (3):317-21.

De Oliveira ARM. Quinina: 470 anos de história, controvérsias e desenvolvimento. Química Nova, 2009, $32: 5$ [in Portuguese].

Duncan R, Gaspar R. Nanomedicine(s) under the microscope. Molecular Pharmaceutics, 2011, 2101:2141.

Fessi H, Devissaguet J-Ph, Puisieux F. Procédé de préparation dês systémes colloidaux dispersibles d'une substances ous forme de nanocapsules. European Patent, 1988, 0274961 A1.

Haas SE, Bettoni CC, De Oliveira LK, Guterres SS, Dalla Costa T. Nanoencapsulation increases quinine antimalarial efficacy against Plasmodium berghei in vivo. International Journal of Antimicrobial Agents, 2009, 34:156-161.

Hall JB, Dobrovolskaia MA, Patri AK, McNeil SE. Characterization of nanoparticles for therapeutics. Nanomedicine (Lond), 2007, 2(6):789-803.

ICH 1996. Harmonized tripartite guideline: validation of analytical procedure: methodology Q2B, Step 4.

ICH 2003. Harmonized tripartite guideline: stability testing of new drug substance and products: methodology Q1A (R2).

ICH 2005. Harmonized tripartite guideline: validation of analytical procedure. Text and methodology Q2(R1).

Meshnick SR, Dobson MJ. The History of Antimalarial Drugs. Humana Press Inc, 2001, 15:25.

Mirghani RA, Ericsson O, Gustafsson LL. High-performance liquid chromatography method for the determination of the major quinine metabolite, 3-hydroxyquinine, in plasma and urine. Journal of Chromatography B: Biomedical Sciences and Applications, 1998, 708: 209-216.
Mosqueira VCF, Legrand P, Gulik A et al. Relationship between complement activation, cellular uptake and surface physicochemical aspects of novel PEG-modified nanocapsules. Biomaterials, 2001, 22:2967-79.

Nagavarma BVYH, Ayadaz A, Vasudha LS, Shivakumar HG. Different Techniques for Preparation of Polymeric Nanoparticles - A Review. Asian Journal of Pharmaceutical and Clinical Research, 2012, $5: 23$.

Salako LA, Sowunmi A. Disposition of quinine in plasma, red blood cells and saliva after oral and intravenous administration to healthy adult Africans. European Journal of Clinical Pharmacology, 1992, 42:(2)171-4.

Schaffazick SR, Pohlmann AR, Freitas LL, Guterres SS. Caracterização e estudo de estabilidade de suspensões de nanocápsulas e de nanoesferas poliméricas contendo diclofenaco. Acta Farmaceutica Bonaerense, 2002, 21:99-106 [in Portuguese].

Taylor WR, White NJ. Antimalarial drug toxicity: a review. Drug Safety, 2004, (1):25-61.

Vale N, Moreira R, Gomes P. Quimioterapia da malária um século no desenvolvimento de antimaláricos. Química 099, 2005, 57:67.

Wiesner J, Fucik K, Kettler $\mathrm{K}$, et al. Structure-activity relationships of novel anti-malarial agents. Part 6: N-(4arylpropionylamino-3-benzoylphenyl)-[5-(4-nitrophenyl)-2-furyl]acrylic acid amides. Bioorganic \& Medicinal Chemistry Letters, 2003, 13(9):1539-41.

World Health Organization. 2010.Guidelines for the treatment of malaria - 2nd edition. Geneva: World Health Organization.

World Malaria Report. 2012. World Health Organization. Geneva: World Health Organization.

\section{How to cite this article:}

Luana Roberta Michels, Lisiane Bajerski, Tamara Ramos Maciel, Leticia Marques Colome, Sandra Elisa Haas. Quinine-Loaded Polymeric Nanoparticles: Validation of a simple HPLC-PDA Method to Determine Drug Entrapment and Evaluation of Its Photostability. J App Pharm Sci, 2016; 6 (02): 009-015. 